\title{
The Behavior of Procurement Process as Described by Using System Dynamics Methodology
}

\author{
Mohd Izhan Mohd Yusoff $(D$ \\ Telekom Research \& Development Sdn Bhd, TM Innovation Center, Lingkaran Teknokrat Timur, 63000 Cyberjaya, \\ Selangor Darul Ehsan, Malaysia \\ Correspondence should be addressed to Mohd Izhan Mohd Yusoff; izhan@tmrnd.com.my
}

Received 19 December 2017; Revised 22 February 2018; Accepted 4 March 2018; Published 22 April 2018

Academic Editor: Viliam Makis

Copyright (C) 2018 Mohd Izhan Mohd Yusoff. This is an open access article distributed under the Creative Commons Attribution License, which permits unrestricted use, distribution, and reproduction in any medium, provided the original work is properly cited.

\begin{abstract}
System dynamics methodology has been used in many fields of study which include supply chain, project management and performance, and procurement process. The said methodology enables the researchers to identify and study the impact of the variables or factors on the outcome of the model they developed. In this paper, we showed the use of system dynamics methodology in studying the behavior of procurement process that is totally different from those mentioned in previous studies. By using a typical procurement process employed by a telecommunication company as a case study, we proposed a new one (i.e., procurement process) and developed a procurement model where we discovered that the number of days involved in completing the whole procurement process depends heavily upon the scenarios we created (especially those that exceed two months), and suggested future research undertakings.
\end{abstract}

\section{Introduction}

Procurement process plays a vital or important role in ensuring that a telecommunication company gets its supplies (for projects) in timely manner, at the best price (offered by the wining vendor), and free from all elements of foul play (or bribery). At the beginning, the procurement process activities employed by a telecommunication company were done manually; for example, the vendors involved in call for quotation exercise were required to (apart from registering themselves to the telecommunication company) submit their quotations (in hardcopy format) by placing them in labelled boxes located at the said company's finance or procurement department. The labels were stated, for example, the supply and installation of hardware or software (with technical specifications as required by the telecommunication company). Then online procurement process system was introduced. The vendors involved in call for quotation exercise were required to upload their quotations (in softcopy format) into the said system. The following are procurement process activities that did not change (over time) and are done manually: the evaluation of quotations and preparation of reports by technical and commercial evaluation committee and the approval of the reports (submitted by technical and commercial evaluation committee) by approval committee. Recently, new "gates" are introduced to evaluate the reports submitted by technical and commercial evaluation committee before they are presented to approval committee, with the aim or purpose of expediting the approval process, as well as to eliminate all elements of foul play (or bribery).

No (scientific) study was done or conducted to evaluate the performance of the existing and new procurement processes especially before the deployment of the latter. The introduction of online procurement process system did not solve all the problems faced by the existing procurement process. For example, the number of papers that the approval committee could handle or manage at any given time is limited. The meeting would normally be held during working days, once a month, and for a specific number of hours only. More and more reports from the existing meeting are forwarded to the next meeting due to either time constraint or lack of quorum. More and more reports are rejected by approval committee due to failing to meet the criteria fixed by approval committee. 
Our research undertakings are focused on solving the problems as mentioned above via the introduction of a new procurement process. They are solved in stages where the new procurement process is updated or expanded on each stage. On the first stage and the main highlight of this paper, the problem we wish to solve is the frequency of approval committee meetings. The rest of the problems are solved in future research undertakings. We performed the following steps for the first stage: firstly, we studied the procurement process of a telecommunication company (via Standard Operating Procedure, or SOP, documents supplied by them). Secondly, we collected (one year) real data, which include the number of days required for an applicant to complete the whole procurement process. Thirdly, we designed and built the procurement model using system dynamics methodology and a portion of (or all) real data collected from previous step. Finally, we studied the performance of the procurement model, which includes comparing the (procurement) model's results with the real data collected from previous step.

\section{Literature Survey}

Supply chain, which manages the flow of finished products or services, is part and parcel of product development cycle and it is normally invoked when the product is completed (i.e., when the product has gone through all tests related to quality with flying colors). Asgari and Hoque [1] demonstrated the use of system dynamics methodology to understand the behavior of all variables involved in Ready-Made-Garment (RMG) industry (such as enablers, performance or results, and inhibitors), especially those related to supply chain, so that top management could make effective decisions to improve the supply chain of the said industry. They conducted a survey and individual interviews with senior management personnel, supply chain professionals, and merchandisers of RMG industry. Kussainov [2] on the other hand modeled and analyzed vaccine supply chain management in view of significant (or important) contribution of immunization programs to public health advancement. The contributions of the said programs are, among others, increasing longevity, reducing child mortality rates, economic growth, development, and prosperity across the board for most of the world.

Malik and Cheng [3] used system dynamics methodology to understand the factors that alter the project as well as the relationship between different knowledge areas in a construction project. They believed the model they developed, apart from improving project performance, addressed the weaknesses displayed by Project Management Body of Knowledge, or PMOK, which introduced ten knowledge areas. Latorre et al. [4] identified obstacles which prevent achievement of the overall performance desired for the UK's construction industry (especially how project managers' decisions impact such performance). The model visualizes the interactions of all relevant goals and elements, presents the need for increased efficiency in the construction industry, and presents the role that KPIs have in driving these required efficiencies. Using system dynamics methodology, Cahyo et al. [5] modeled the resource provision policy in multiunit maintenance program (emphasizing resource strategy involving human and procurement). The model is divided into several submodels, namely, human resource submodel, which focuses on policies related to provision and management, and procurement submodel, which emphasizes the procurement process and inventory system. The model showed the impact of one decision in a certain maintenance resourcing system on the other maintenance resourcing system and will lead to an optimum policy for maintenance resource provision system. Sadreddin et al. [6] used a large Canadian construction company as case study to develop the cost of quality (coq) model for the procurement process of the construction industry and establish a general course of action for minimizing quality costs. The use of the preventionappraisal-failure approach for the coq model of the procurement process, the internal quality costs within the company, and costs of its suppliers were considered. Several different policies were designed and their effects on quality costs were investigated via system dynamics methodology. Their findings suggested that prevention costs should be increased to minimize failures, and they also found that appraisal cost is quite high in the procurement process and should be reduced in order to minimize overall coq. However this strategy could increase failure occurrences thereby damaging company's reputation. The possible reductions of appraisal cost in the construction companies should thus be carefully considered. Ross-Smith and Yearworth [7] listed several weaknesses which include traditional independent project performance evaluations which are time consuming and disruptive to business as usual and used system dynamics methodology to combine performance evaluation and continual tracking into one performance auditing method, thus allowing a model of a system to be continually updated and internally and independently analyzed as required. Using the Bernard gray report of defense procurement as a test case, they found that qualitative system dynamics has utility in creating an enterprise performance audit.

Croom and Johnston [8] addressed the issues relating to the impact of e-business developments on internal customer service with a focus on electronic procurement introduction. In other words, it concentrates on the intraorganizational system dynamics of e-business. Marquez and Blanchar [9] presented simulation study to extend current methods for real options strategies in the management of strategic commodity type parts. They simulated 3 generic types of supplier contracts to accomplish varying degrees of security and flexibility and simulated a portfolio of these contracts applied to secure a single part, with the purpose of extending and refining portfolio valuation. Mula et al. [10] used Vensim ${ }^{\circledR}$ simulation tool to propose a simulation approach based on system dynamics for operational procurement and transport planning in a two-level, multiproduct and multiperiod supply chain. The results are compared with spreadsheet based simulation, fuzzy multiobjective programming, and system dynamics based simulation models. Marinkovic [11] concentrated on a specific antihail public service provider in Siberia, exploring not only the outcome of the public provider's procurement practices, but also outputs of such actions on the territory level, and built a model of corruption 


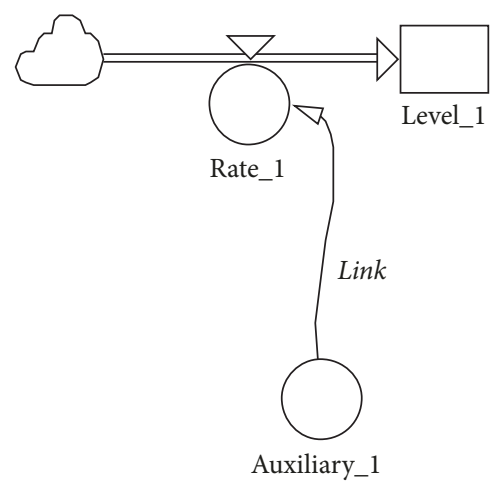

Figure 1: An example of a model developed using system dynamics methodology.

based on Dynamics Performance Management approach in order to extend their understanding of corruption and its background as well as to provide an input to future policymaking on corruption issues.

In this paper, which is divided into Methodology, The Procurement Model, Results, and Conclusion sections, we will show the use of system dynamics methodology in studying the behavior of procurement process that is totally different from those mentioned in the above studies.

\section{Methodology}

System dynamics methodology is defined as a field for understanding how things change through time. It deals with how the internal feedback loops within the structure of a system create behavior and focuses on the feedback behavior of variables within the closed loop of the system. The strength of SD is its way of analyzing the impact of information feedback on decision making of a complex system. The following are some of the common symbols used in system dynamics methodology.

Stock, represented by Level_1 in Figure 1, is an element that accumulates and depletes over time. Flow, represented by Rate_1, is the rate of change in a stock. Link defines dependency between elements of a stock and flow diagram; and Auxiliary, represented by Auxiliary_1, is used to define some intermediate concepts. Positive feedback loops enhance or amplify changes, which tends to move a system away from its equilibrium state and make it more unstable. Negative feedback loops dampen or buffer changes, which tends to hold a system to some equilibrium state making it more stable [12]; practical example is given in the Appendix.

Note that Powersim Studio Enterprise 2005 is the application used to develop procurement model.

\section{The Procurement Model}

The purchasing of hardware and software for projects undertaken by a telecommunication company must go through procurement process involving call for quotation, technical and commercial evaluation committee, and approval committee. For example, if the price of hardware is less than say
$\$ 1000$, two quotations are collected from authorized vendors via call for quotation process (the duration for the said process is 14 days). They (i.e., quotations) are evaluated and only one is selected by technical and commercial evaluation committee. Approval committee chaired by Manager of Procurement studies the reports submitted by technical and commercial evaluation committee and approves the purchasing of hardware from selected vendor. If the price of hardware is greater than say $\$ 100,000$, more quotations are required by technical and commercial evaluation committee from authorized vendors, and approval committee is chaired by Chief Executive Officer. Figure 2 shows a normal or typical procurement process where the blue arrow lines represent first path taken by user or applicant whilst the red arrow lines represent second path, which is taken when approval committee rejects the recommendation from technical and commercial evaluation committee (in this paper, we are focusing on readvertisement because this action clearly adds more days to the whole procurement process). The rejection might be due to several reasons; one of them is that the number of quotations submitted by vendors did not meet the criteria fixed by approval committee. The details of the procurement process used by a telecommunication company will not be revealed in this paper and they will be treated as confidential information.

The procurement model, as shown in Figures 4 and 5 (using an algorithm as shown in Figure 3), which represent two (2) scenarios, used random numbers between zero and one (to create application date and chances and add realism to the simulation), fixed 30 days for each month, ignored Saturday and Sunday as well as official (or unofficial) holidays, fixed the 10th and 20th of each month for approval committee to convene or meet (i.e., twice for each month) (in real data, approval committee meets once a month on working days where they reserved time, date, and venue to discuss the submitted reports, (the reservation depends heavily upon the availability of committee members), and the measurement used to represent cycle time is working days), and fixed either the 3rd or 13th of each month for the (technical and commercial evaluation committee) reports to reach the secretariat (of the approval committee). If the reports reached on the 3rd or 13th, they are tabled (or presented) on the 10 th or 20th, respectively. Call for quotation process starts on the same day as the applicant submits his or her form to the relevant authority. The price of hardware or software to be procured was not considered in the said model (further clarification on the assumptions used: (1) if there are at least 7 days to complete 10 items in the reports, 7 of them are not met with less than 7 days leading to postponement of the submission date. There are cases where 10 items are met in less than 7 days; (2) if there are 10 criteria fixed by approval committee, 7 of them are not met leading to an extension of procurement process; (3) the fixing of date of submission and date of convene (for approval committee) could only be done or achieved if online (process) system (replacing manual process) is used. Reports can be uploaded into online system by the applicant where approval committee could study and approve them via the same system (on the stipulated or agreed date)). 


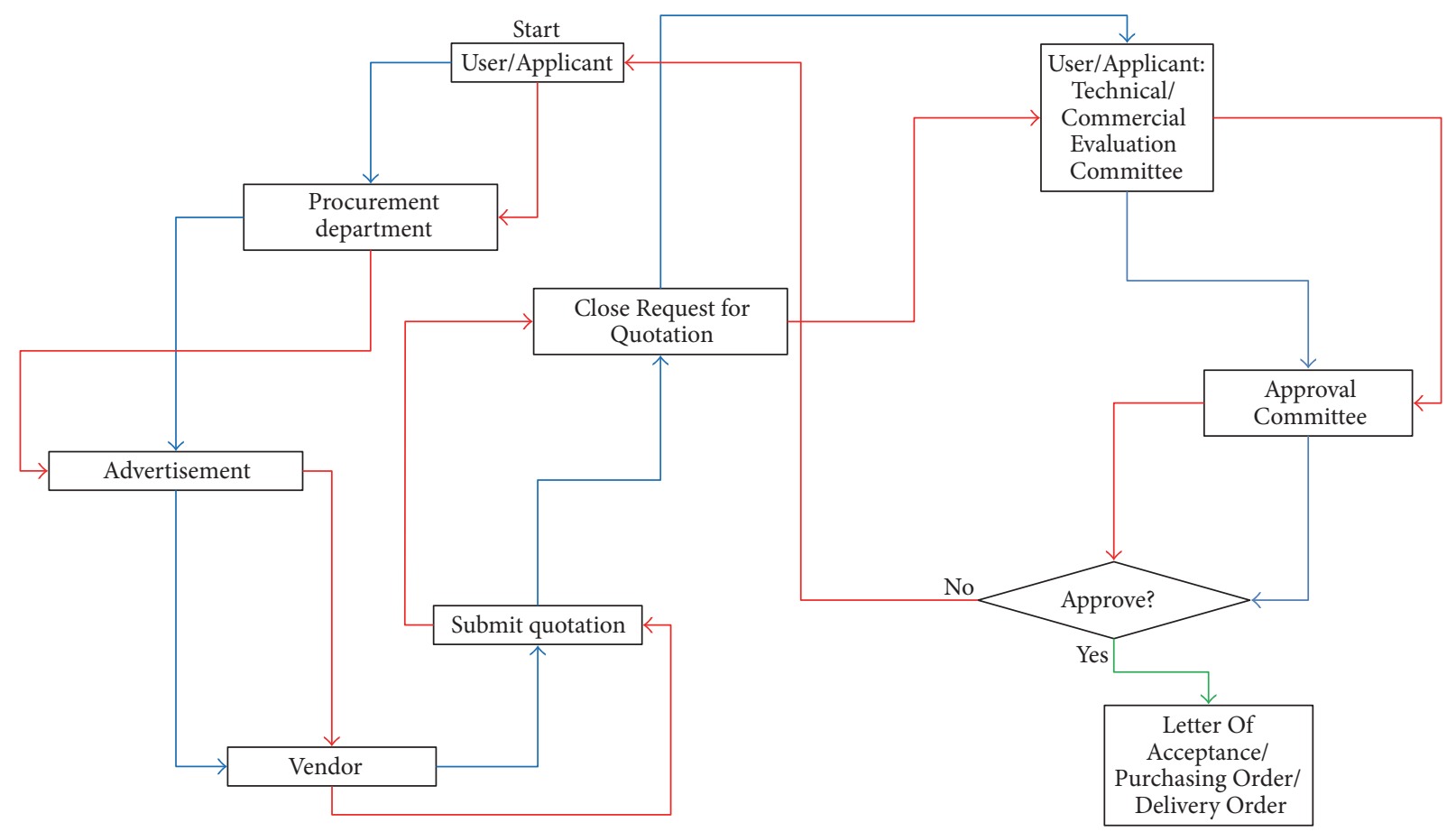

FIGURE 2: Flow diagram shows a normal (or typical) procurement process employed by a telecommunication company.

Scenario 1. Figure 4 is best described via the following example: the applicant submits his or her form to the relevant authority say in January and, based on the information given in the form, the relevant authority calls for quotations from authorized vendors for a period of 14 days. Once completed, that is, before the 30th of January, in terms of call for quotation process, the technical and commercial evaluation committee (where the applicant is also a member) reports (which include evaluation of the quotations submitted by the authorized vendors) are submitted to the secretariat (of approval committee) on the 3rd of February where the (approval) committee meets on the 10th of February.

When the reports are presented (or tabled) before the approval committee on the 10th of February and due to the fact that, among others, the number of quotations received (from the first call for quotation process) did not meet the targeted value (or criteria), there are more than $70 \%$ chances that the (approval) committee will request the applicant to repeat the call for quotation process for (an additional) seven days. The updated technical and commercial evaluation committee reports (which include evaluation of the quotations submitted by the authorized vendors) are submitted to the secretariat (of approval committee) on the 3rd of March to be presented and approved by the approval committee seven days later, that is, on the 10th of March. Otherwise, the reports are approved by the approval committee on the 10th of February. This scenario assumes that the number of days to complete the reports is greater than (or equal to) seven days.

If the number of days to complete the reports (after 14 days of call for quotation process) is less than seven days, there are more than $70 \%$ chances that the technical and commercial evaluation committee reports (which include evaluation of the quotations submitted by the authorized vendors) are not complete (or ready) for submission (to the secretariat of approval committee) on the 3rd of February. The reports are submitted to the secretariat of approval committee on the 13th of February instead and presented before the said committee on the 20th of February. When the reports are presented before the approval committee on the 20th of February and due to the fact that, among others, the number of quotations received (from the first call for quotation process) did not meet the targeted value (or criteria), there are more than $70 \%$ chances that the (approval) committee will request the applicant to repeat the call for quotation process for (an additional) seven days. The updated technical and commercial evaluation committee reports (which include evaluation of the quotations submitted by the authorized vendors) are submitted to the secretariat (of approval committee) on the 3rd of March to be presented and approved by the approval committee seven days later, that is, on the 10th of March. Otherwise, the reports are approved by the approval committee on the 20th of February.

Scenario 2. Figure 5 is best described thru the following example: the applicant submits his or her form to the relevant authority say in January and, based on the information given in the form, the relevant authority call for quotations from authorized vendors for a period of 14 days. Once completed, that is, well after the 30th of January, in terms of call for quotation process, the complete technical and commercial evaluation committee reports (which include evaluation of the quotations submitted by the authorized vendors) are submitted to the secretariat (of approval committee) on either the 3rd of February, 13th of February, or 3rd of March, 

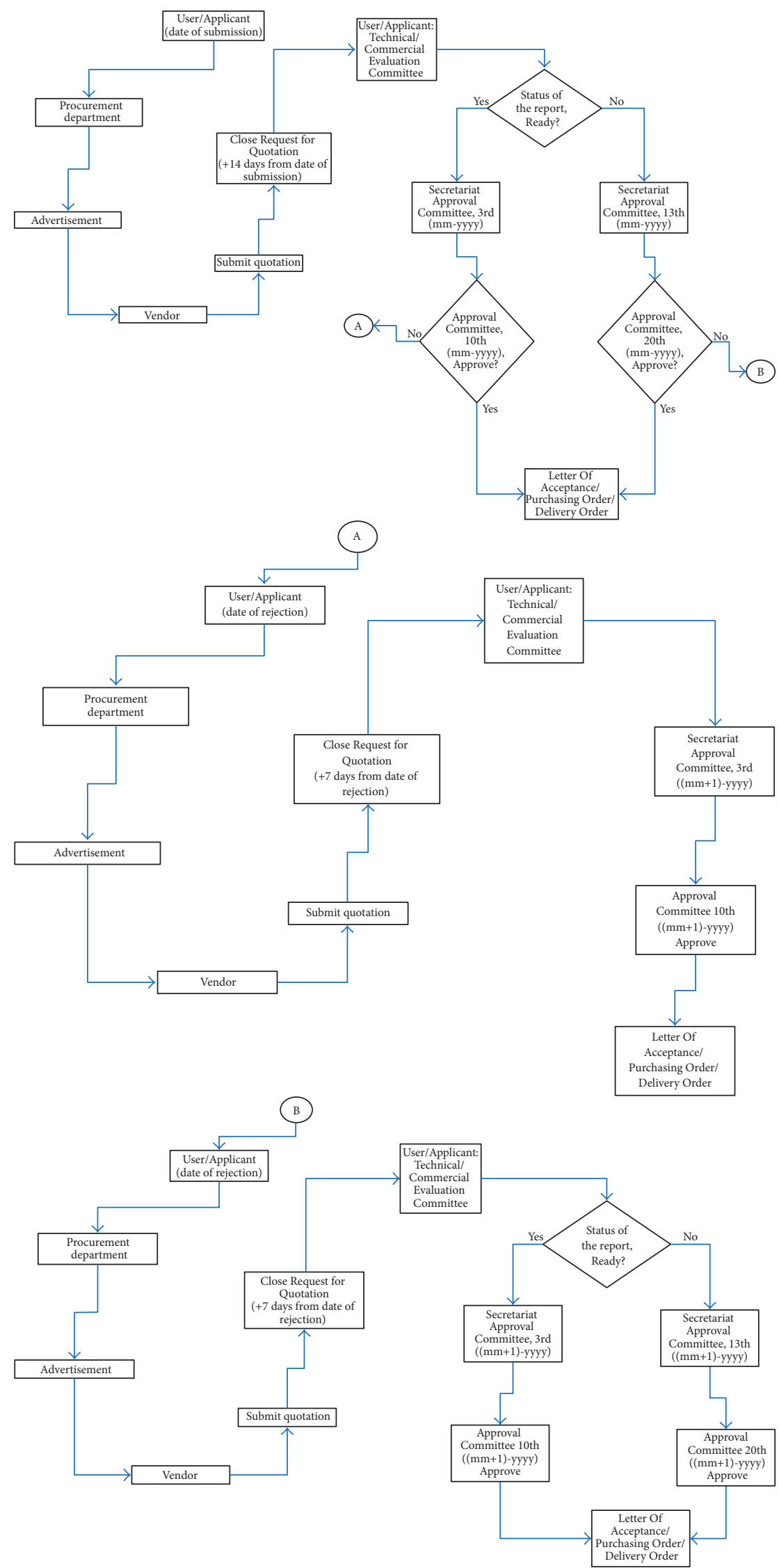

FIGURE 3: Due to its size, only a portion of the algorithm used in developing the procurement model is presented in this paper, and in the form of the above flow diagram. 

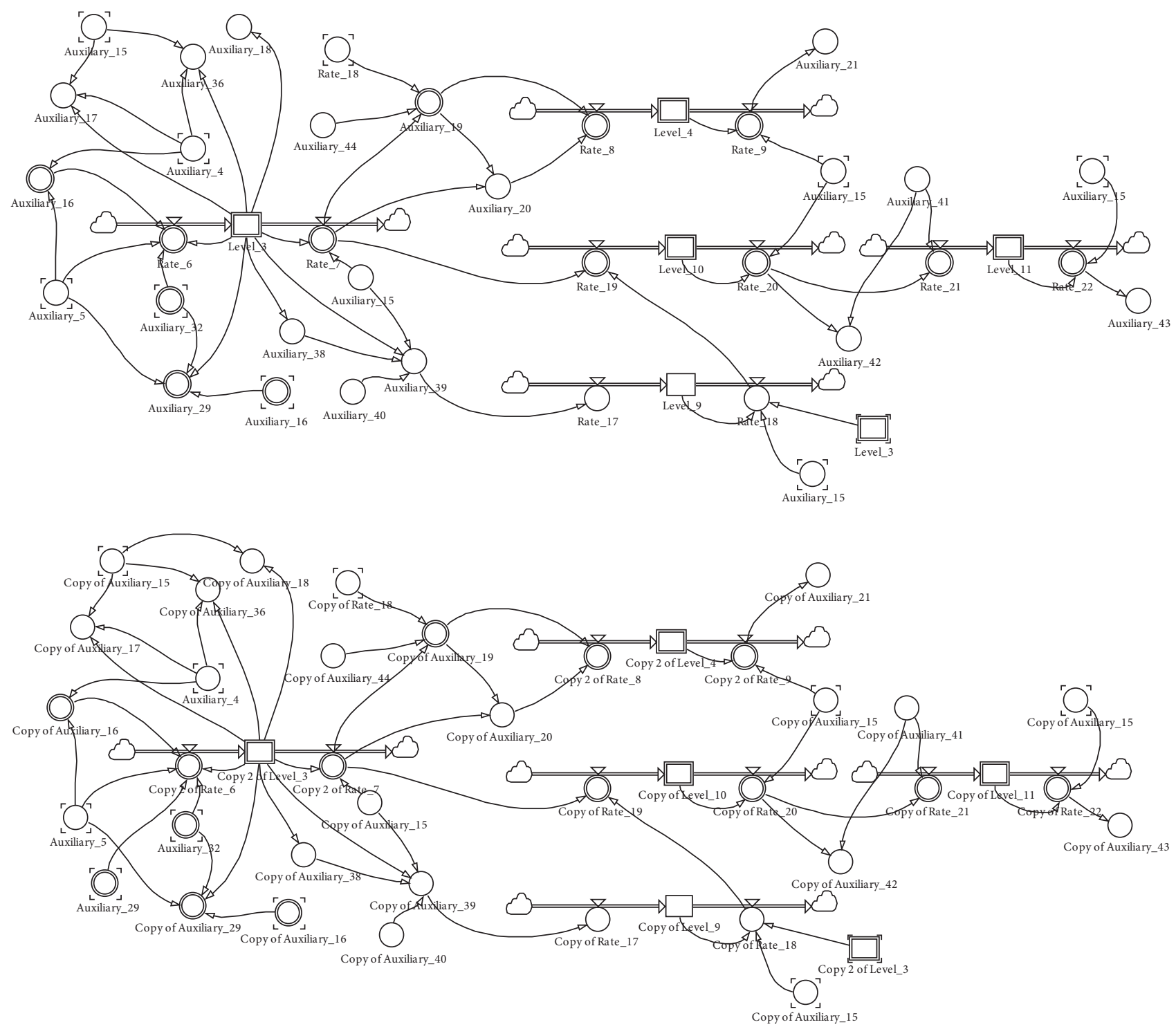

FIGURE 4: The procurement model developed using system dynamics methodology (Scenario 1).

where the (approval) committee meets on either the 10th of February, 20th of February, or 10th of March, respectively.

When the reports are presented (or tabled) before the approval committee on either the 10th of February, 20th of February, or 10th of March and due to the fact that, among others, the number of quotations received (from the first call for quotation process) did not meet the targeted value (or criteria), there are more than $70 \%$ chances that the (approval) committee will request the applicant to repeat the call for quotation process for (an additional) seven days. The updated technical and commercial evaluation committee reports (which include evaluation of the quotations submitted by the authorized vendors) are submitted to the secretariat (of approval committee) on either the 3rd of March or 3rd of April to be presented and approved by the approval committee seven days later, that is, on the 10th of March or the 10th of April. Otherwise, the reports are approved by the approval committee on either the 10th of February, 20th of February, or 10th of March. This scenario assumes that the number of days to complete the reports is greater than (or equal to) seven days.

If the number of days to complete the reports (after 14 days of call for quotation process) is less than seven days, there are more than $70 \%$ chances that the technical and commercial evaluation committee reports (which include evaluation of the quotations submitted by the authorized vendors) are not complete (or ready) for submission (to the secretariat of approval committee) on either the 3rd or 13th of February. The reports are submitted to the secretariat of approval committee on either the 13th of February or 3rd of March instead and presented before the said committee on either the 20th of February or 10th of March. When the reports are presented before the approval committee on either the 20th of February or 10th of March and due to the 

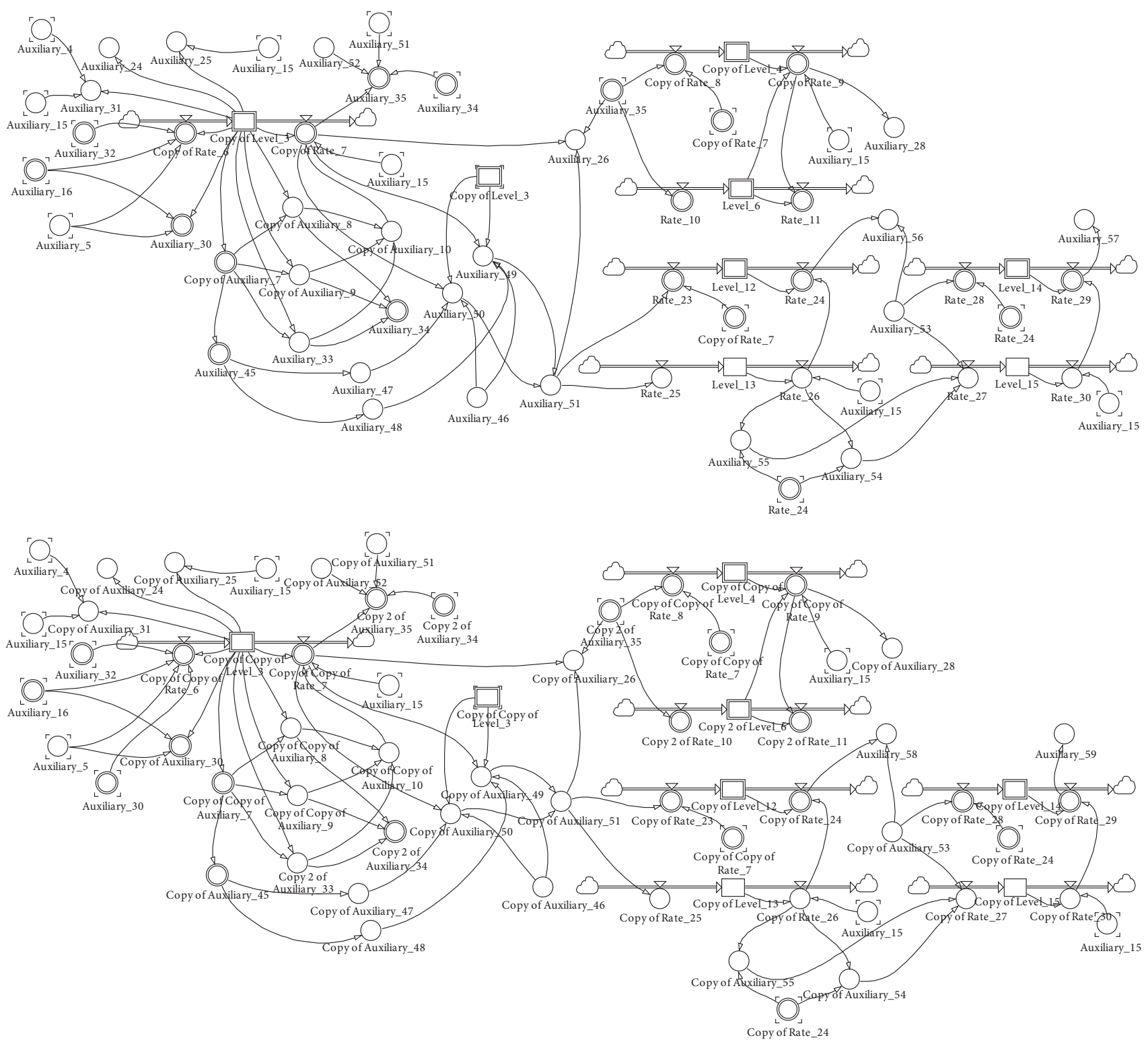

FIGURE 5: The procurement model developed using system dynamics methodology (Scenario 2).

fact that, among others, the number of quotations received (from the first call for quotation process) did not meet the targeted value (or criteria), there are more than $70 \%$ chances that the (approval) committee will request the applicant to repeat the call for quotation process for (an additional) seven days. The updated technical and commercial evaluation committee reports (which include evaluation of the quotations submitted by the authorized vendors) are submitted to the secretariat (of approval committee) on either the 3rd of March or 3rd of April to be presented and approved by the approval committee seven days later, that is, on the 10th of March or 10th of April. Otherwise, the reports are approved by the approval committee on either the 20th of February or 10th of March.

\section{Results}

We performed 100 runs (which produced at most 1,200 observations) and some of them (i.e., results) are given in this paper. Example of one (1) run is shown in Figures 6, 7, 8, and 9 where each procurement process is represented by three spikes of different colors, namely, green (representing the date of submission), yellow (representing the date when call for quotation process is completed), and red (representing the date when approval committee approved the reports). All submissions are randomly made; hence they are independent of each other.

The first three spikes in Figure 6 represent the following behavior: the application was submitted on the 15th of January and call for quotation process was completed on the 


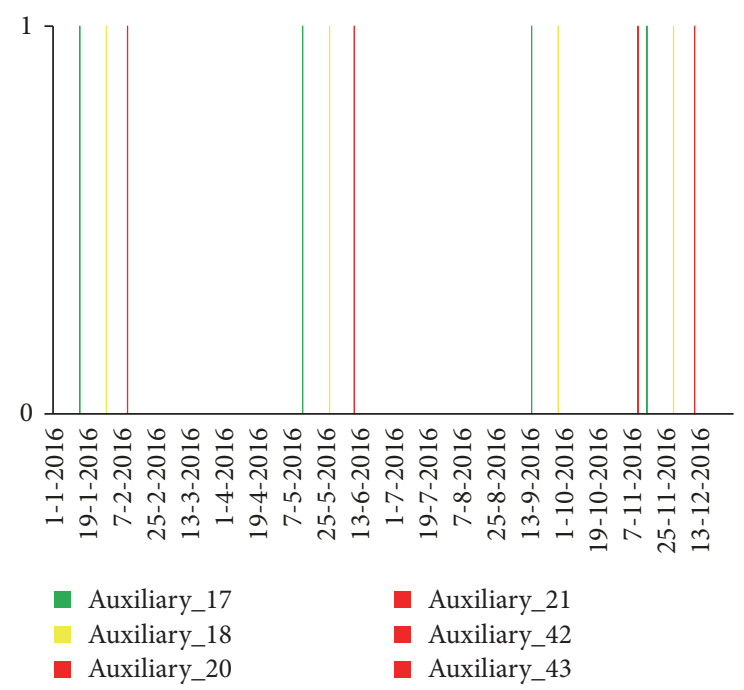

FIGURE 6: Behavior produced from the procurement model's Scenario 1.

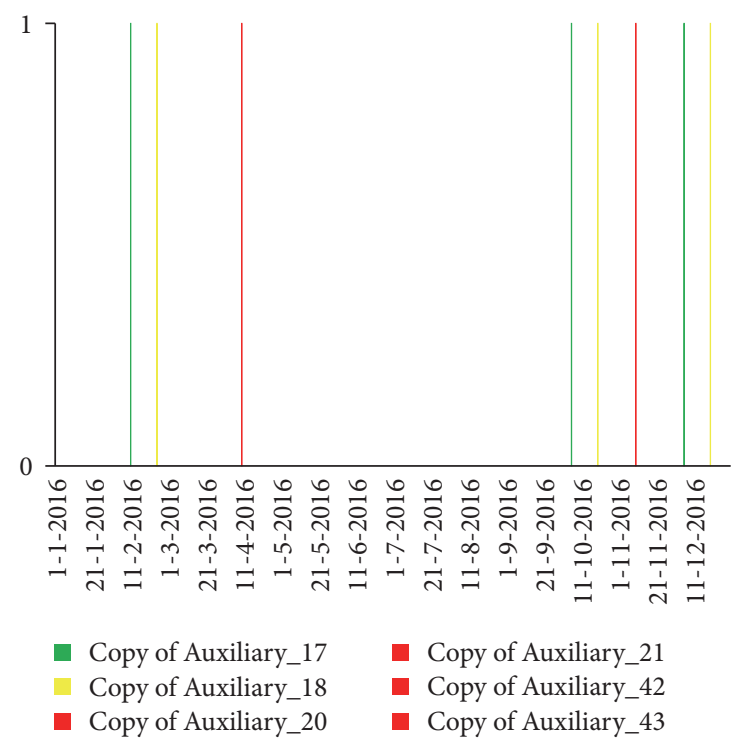

FIGURE 7: Behavior produced from the procurement model's Scenario 1 (continued).

29th of January. The applicant cum technical and commercial evaluation committee (henceforth, the applicant) managed to complete the reports and submitted them on the $3 \mathrm{rd}$ of February. The approval committee approved the reports on the 10th of February. The total number of days involved is 25 . The second three spikes (in the same figure) represent the following behavior: the application was submitted on the 13 th of May and call for quotation process was completed on the 27th of May. The applicant managed to complete the reports and submitted them on the 3rd of June. The approval committee approved the reports on the 10th of June. The total number of days involved is 27 . The third three spikes represent the following behavior: the application was submitted on the 14th of September and call for quotation process was

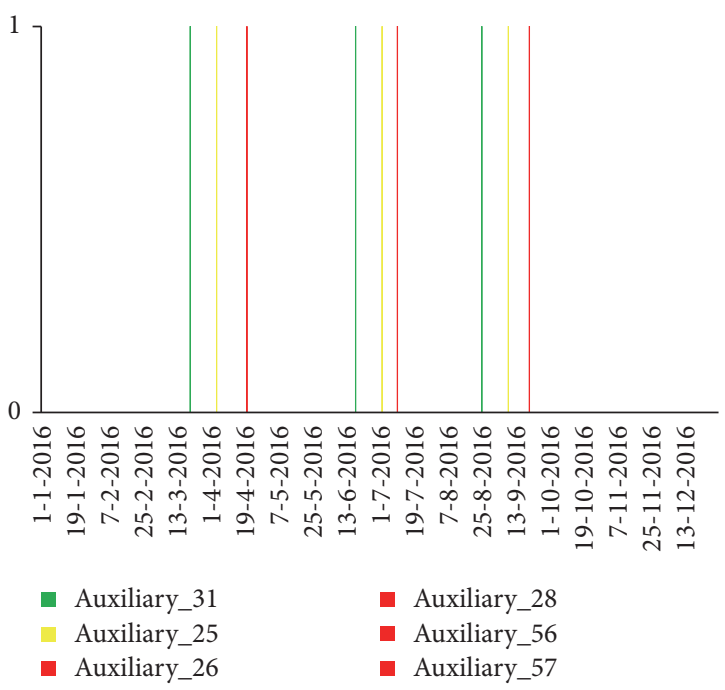

FIgURE 8: Behavior produced from the procurement model's Scenario 2 .

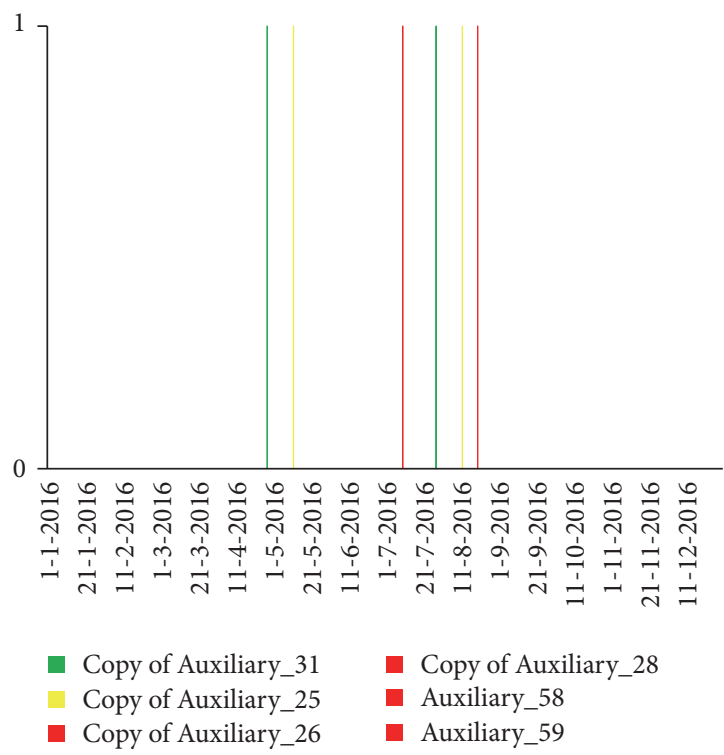

FIGURE 9: Behavior produced from the procurement model's Scenario 2 (continued).

completed on the 28th of September. The applicant did not manage to complete the reports on the 3rd of October and submitted them on the 13 th of October instead. The approval committee did not approve the reports on the 20th of October. The applicant submitted the updated reports on the 3rd of November. The approval committee approved the reports on the 10th of November. The total number of days involved is 56 . The fourth (final) three spikes represent the following behavior: the application was submitted on the 15th of November and call for quotation process was completed on the 29th of November. The applicant managed to complete the reports and submitted them on the 3rd of December. The approval committee approved the reports on the 10th of December. The total number of days involved is 25 . 
Figure 7's first three spikes represent the following behavior: the application was submitted on the 11th of February and call for quotation process was completed on the 25th of February. The applicant completed and submitted the reports on the 3rd of March. The approval committee did not approve the reports on the 10th of March. The applicant submitted the updated reports on the 3 rd of April. The approval committee approved the reports on the 10th of April. The total number of days involved is 59. The second three spikes (in the same figure) represent the following behavior: the application was submitted on the 6th of October and call for quotation process was completed on the 20th of October. The applicant managed to complete the reports and submitted them on the 3rd of November. The approval committee approved the reports on the 10th of November. The number of days involved is 34 . The third (final) three spikes represent the following behavior: the application was submitted on the 6th of December and call for quotation process was completed on the 20th of December. The rest of the (procurement) processes were brought forward to the next year. The total number of days involved is not calculated.

The first three spikes in Figure 8 represent the following behavior: the application was submitted on the 20th of March and call for quotation process was completed on the 4th of April. The applicant managed to complete the reports and submitted them on the 13th of April. The approval committee approved the reports on the 20th of April. The total number of days involved is 30 . The second three spikes (in the same figure) represent the following behavior: the application was submitted on the 18th of June and call for quotation process was completed on the 2 nd of July. The applicant managed to complete the reports and submitted them on the 3rd of July. The approval committee approved the reports on the 10th of July. The total number of days involved is 22 . The third (last) three spikes represent the following behavior: the application was submitted on the 25th of August and call for quotation process was completed on the 9th of September. The applicant managed to complete the reports and submitted them on the 13th of September. The approval committee approved the reports on the 20th of September. The total number of days involved is 25 .

Figure 9's first three spikes represent the following behavior: the application was submitted on the 28th of April and call for quotation process was completed on the 12th of May. The applicant did not complete and submit the reports on the 13th of May. The applicant submitted them on the 3rd of June instead. The approval committee did not approve the reports on the 10th of June. The applicant submitted the updated reports on the 3rd of July that approval committee approved on the 10th of July. The total number of days involved is 72. The second (final) three spikes represent the following behavior: the application was submitted on the 28th of July and call for quotation process was completed on the 12th of August. The applicant managed to complete the reports and submitted them on the 13th of August. The approval committee approved the reports on the 20th of August. The total number of days involved is 22 .

Summary (or standard) statistics average, standard deviation, minimum, and maximum for the above observations (related to total number of days involved) are 36.1, 17.6, 22, and 72 , respectively.

Results for the rest of the (100) runs (especially related to total number of days involved) are presented in the form of summary (or standard) statistics average, standard deviation, minimum, and maximum, which were produced using four (4) specially designed (system dynamics) models; one of them is shown in Figure 10. Summary (or standard) statistics average, standard deviation, minimum, and maximum for Figure 11's 1052 observations (related to total number of days involved) are 37.25, 13.58, 21, and 77, respectively. "SimData" in Figure 11(a) refers to total number of days involved in completing the procurement process. Two humps are (vividly) observed: first hump lies between 21 days and 47 days (for the procurement process to complete) and second hump between 52 days and 77 days. If number of days for each month is fixed at 30 , there are quite a considerable number of cases/runs where the procurement process would take approximately 29 days as well as 63 days (more than two months) to complete; refer to Figure 11(b) [13].

Figure 11 is dissected into Scenario 1, represented by Figures 12(a) and 12(b). Summary (or standard) statistics average, standard deviation, minimum, and maximum for Figure 12's 570 observations (related to total number of days involved) are 40.49, 13.94, 24, and 69, respectively. Similar to the previous figure, "SimData" refers to total number of days involved in completing the procurement process. Two humps are observed: first hump lies between 24 days and 56 days (for the procurement process to complete) and second hump between 57 days and 69 days. If number of days for each month is fixed at 30 , there are quite a considerable number of cases/runs where the procurement process would take approximately 33 days (more than one month) as well as 62 days (more than two months) to complete; refer to Figure 12(b).

Scenario 2, represented by Figures 13(a) and 13(b), is the final output from Figure 11's dissection. Summary (or standard) statistics average, standard deviation, minimum, and maximum for Figure 13's 482 observations (related to total number of days involved) are $33.43,12.08,21$, and 77 , respectively. Three humps are observed: first hump lies between 21 days and 35 days (for the procurement process to complete), second hump between 36 days and 63 days, and third hump between 71 days and 77 days. If number of days for each month is fixed at 30 , there are quite a considerable number of cases/runs where the procurement process would take approximately 24 days, 42 days (more than one month), and 75 days (more than two months) to complete; refer to Figure 13(b).

The procurement model (simulated) data of 1052 observations (refer to Figure 11) are compared with the real data of 59 observations (refer to Figure 14) to see if the former "behaves" in the same manner as the latter (if their "behavior" is the same, it is as though, or if, the new procurement process is deployed "live"). Note that summary (or standard) statistics averages, standard deviation, minimum, and maximum for Figure 14 (representing real data) are 33.42, 10.35, 13, and 60, respectively. 


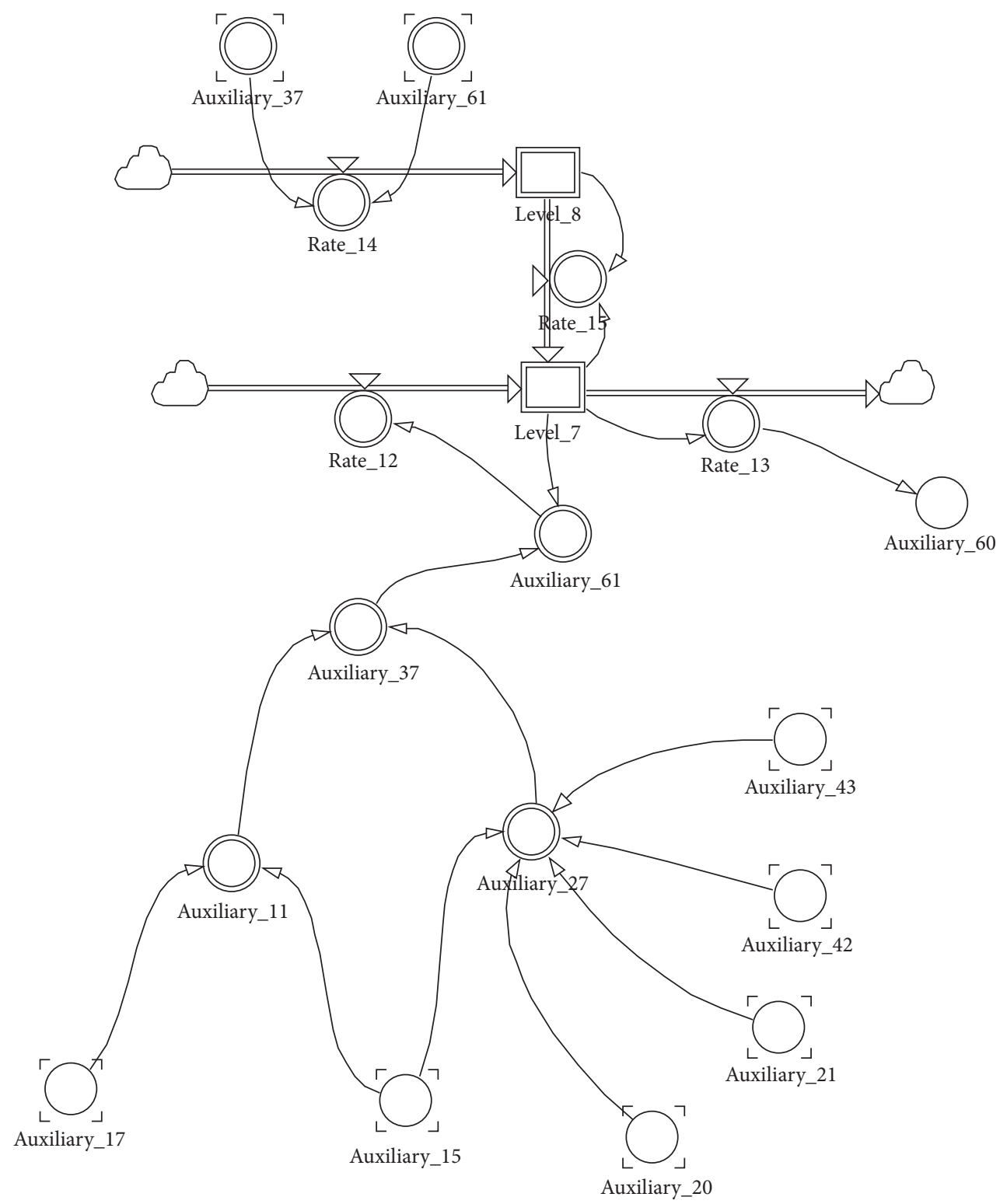

FIGURE 10: Specially designed system dynamics model used to calculate total number of days involved.

Two statistical nonparametric tests are chosen; they are as follows:

(a) Mann-Whitney $U$ test is a nonparametric test of the null hypothesis where it is equally likely that a randomly selected value from one sample is less than or greater than a randomly selected value from a second sample. It does not require the assumption of normal distributions.

(b) Kolmogorov-Smirnov two-sample test statistics is a nonparametric test of the equality of continuous, onedimensional probability distributions that can be used to compare a sample with a reference probability (one-sample $k$-s test) or to compare two samples (two-sample $k$-s test).

Details can be found in Sachs [14].
As mentioned above, Mann-Whitney $U$ test and Kolmogorov-Smirnov two-sample test statistics are used to test that the distributions of both populations are equal and two samples come from a common distribution, respectively. The two populations and samples are referring to Figures 11 and 14. Table 1 shows especially the $p$ value corresponding to Asymptotic Significance (2-tailed) where both of them are greater than 0.05 , the distributions of both populations are equal (Mann-Whitney $U$ test), and two samples come from a common distribution (Kolmogorov-Smirnov two-sample test statistics) (if Asymptotic Significance (2-tailed) is less than $(<) 0.05$, the distributions of both populations are not equal (Mann-Whitney $U$ test) and two samples come from different distribution (Kolmogorov-Smirnov two-sample test statistics)). In other words, their (i.e., Figures 11 and 14) "behavior" is the same. 


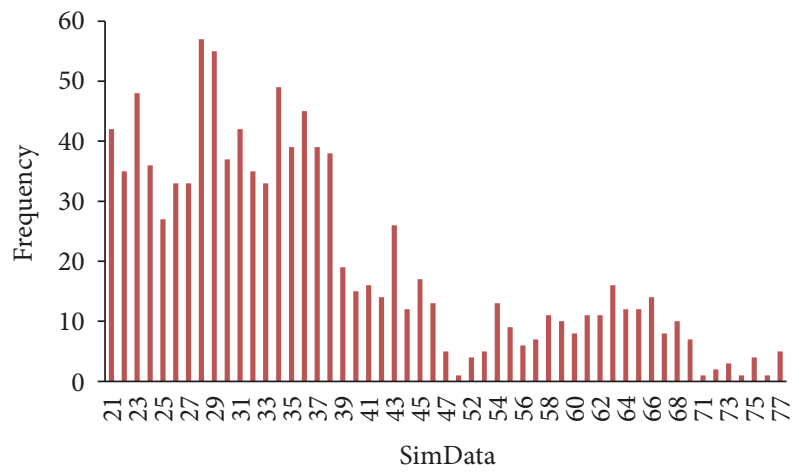

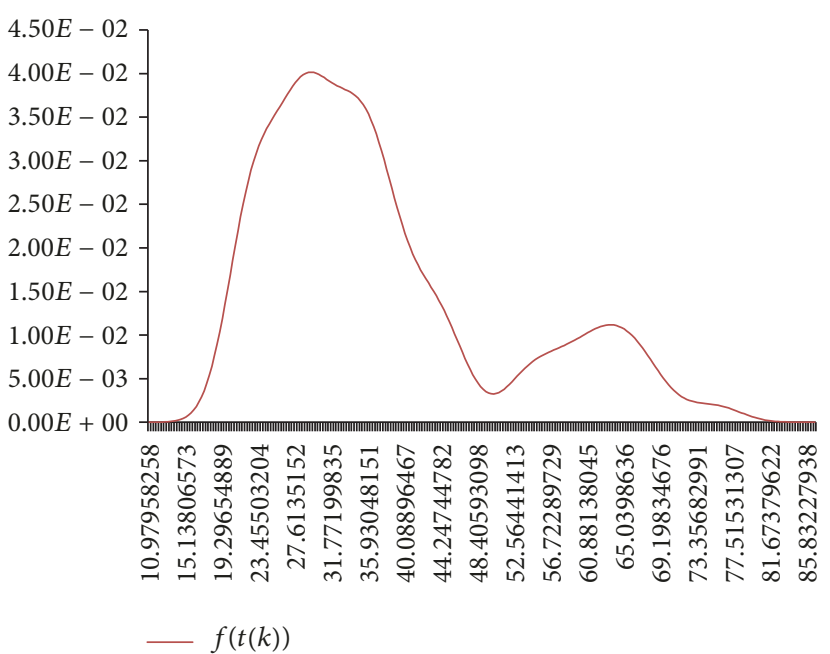

(b)

FIGURE 11: One thousand and fifty-two (1052) observations representing 100 runs are displayed in the form of (a) bar chart and (b) probability density function (pdf).

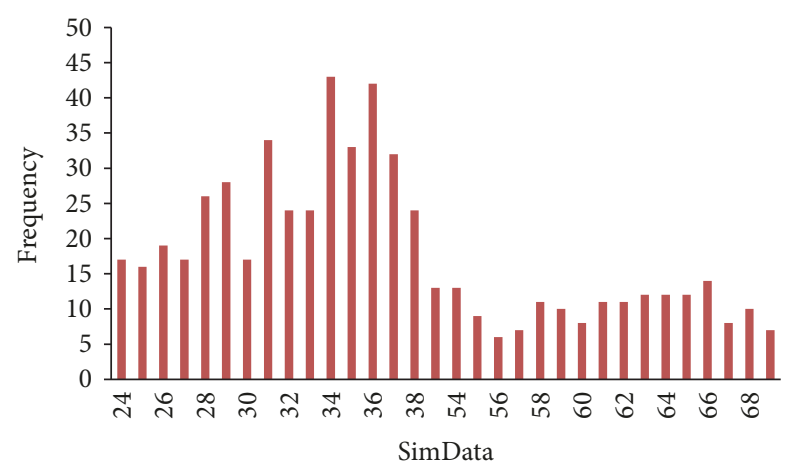

(a)

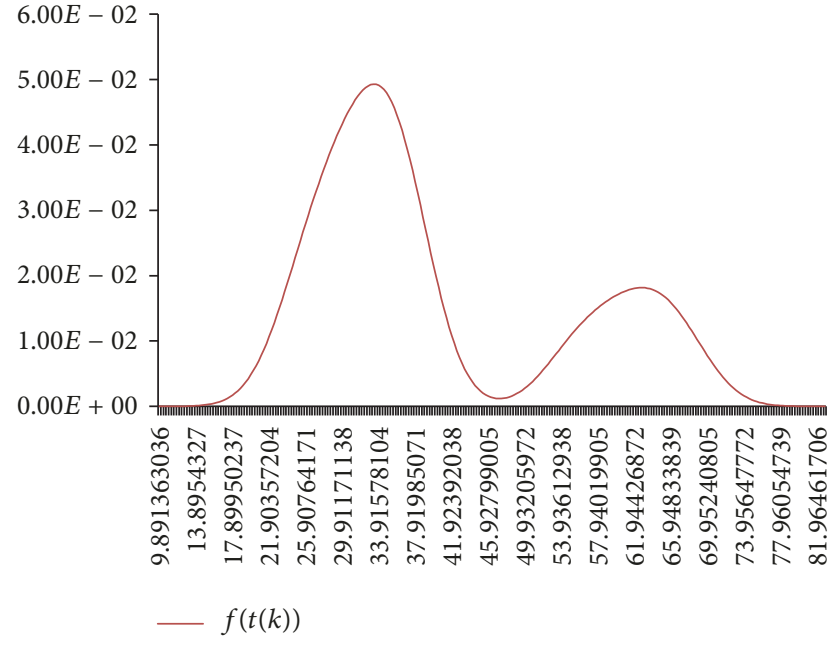

(b)

FIGURE 12: Scenario 1's five hundred and seventy (570) observations are displayed in the form of (a) bar chart and (b) probability density function (pdf).

TABLE 1: Asymptotic Significance (2-tailed) for both Mann-Whitney $U$ test and Kolmogorov-Smirnov two-sample test.

\begin{tabular}{lcc}
\hline & Mann-Whitney $U$ test & $\begin{array}{c}\text { Kolmogorov-Smirnov } \\
\text { two-sample test }\end{array}$ \\
\hline $\begin{array}{l}\text { Asymp. Sig. } \\
\text { (2-tailed) }\end{array}$ & 0.181 & 0.230 \\
\hline
\end{tabular}

\section{Conclusion}

In the previous sections, we listed several studies related to supply chain, project management and performance, and procurement process. We also highlighted a procurement process normally employed by a telecommunication company and introduced new procurement process via procurement model (Scenarios 1 and 2) using system dynamics methodology. In the said model, several assumptions were made (which include (1) using random numbers between zero and one to create application date and chances, (2) fixing 30 days for each month, ignoring Saturday and Sunday as well as official or unofficial holidays, (3) fixing the 10th and 20th of each month for approval committee to convene or meet, and (4) fixing either the 3rd or 13th of each month for the technical and commercial evaluation committee reports to reach the secretariat of the approval committee) and it was executed for 100 runs. The results from the said execution showed the procurement process could be less than 30 


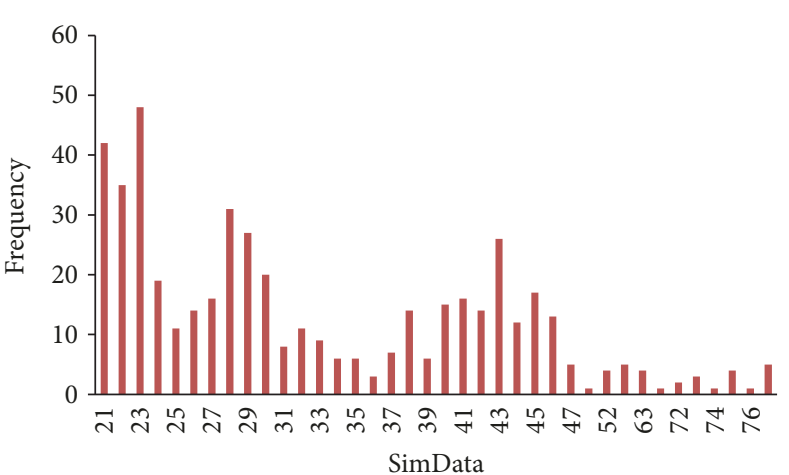

SimData

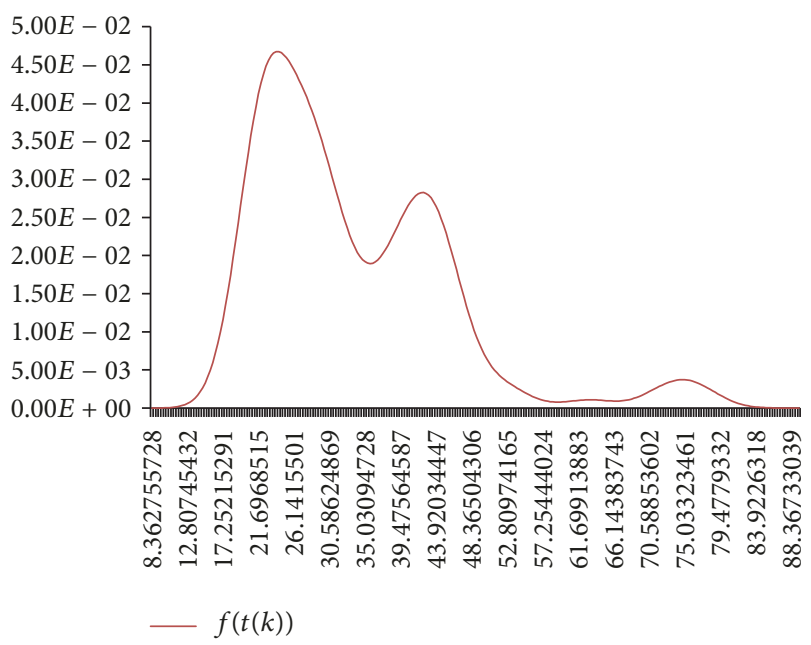

(b)

FIGURE 13: Scenario 2's four hundred and eighty-two (482) observations are displayed in the form of (a) bar chart and (b) probability density function (pdf).

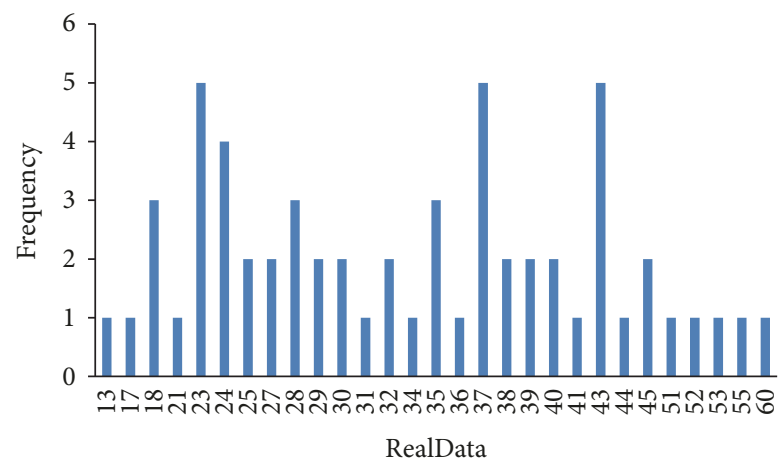

FIGURE 14: Fifty-nine (59) observations of real data are displayed in the form of bar chart.

days (or one month) if technical and commercial evaluation committee reports satisfied approval committee's criteria and more than two months if they did not. The number of runs for scenario one is greater than scenario two especially when the number of days involved for procurement process to complete is greater than two months. In other words, it is most likely (or probable) for procurement process to exceed two months for scenario one as compared to scenario two. The said model is useful if the company's main business involved procuring hardware and software for executing (or completing) its projects. If procuring hardware and software was not done properly (or in timely manner), the projects may suffer (significant) delays and require more monies to complete (as well as negative impact on key performance indicators of those who are involved in the projects). Note that the "behavior" of procurement model data and real data is the same when tested using statistical nonparametric tests.

Apart from building approval committee model using system dynamics methodology (which includes listing all of the variables or factors affecting approval committee's decision making), adding "gates" to ensure all reports tabled in approval committee are approved by the said committee (i.e., to ensure all criteria are met), and building several models for different price of hardware and software to be procured, the above model could also be incorporated into the model as shown in Figure 15 for future research undertakings (especially to visualize the benefits such that more reports could be handled or managed by approval committee). Figure 15 uses the following assumptions (subjected to changes): (1) 30 days are fixed for every month; (2) Saturday and Sunday as well as official holidays are not considered in the model; (3) applications submitted per month come from 4 projects, namely, A, B, C, and D. They are selected at random (to add realism to the simulation); (4) the applications are generated between the 1st and 30th of each month; (5) 3 applications are generated from 3 different projects selected at random from 4 projects; (6) 2 applications are generated from 2 different projects selected at random from 4 projects; (7) 1 application is generated from a project selected at random from 4 projects; (8) standard cycle time is 3 days and several days are added at random; (9) next model (or Model 2) focuses on each application especially on the cycle time. The cycle time depends on when the application is submitted that is either before or after the 15th of each month (15th is the date the committee holds its meeting) plus the number of days needed to complete the process.

\section{Appendix}

Two scenarios are considered for water tank model as shown in Figure 16; they are as follows.

Scenario A.1. The following are the equations used in water tank model: Rate $11=10$ Liter/Hour; Level_1 $=0$ Liter (at the beginning); Rate_2 = Level_1 Liter/Hour if Level_1 $\geq 100$ Liters; Rate $\_$_ 0 Liter if otherwise. Over a period of 24 hours where the water tank is empty at the beginning, water flows into the tank at the rate of 10 Liters per hour. If water in the 


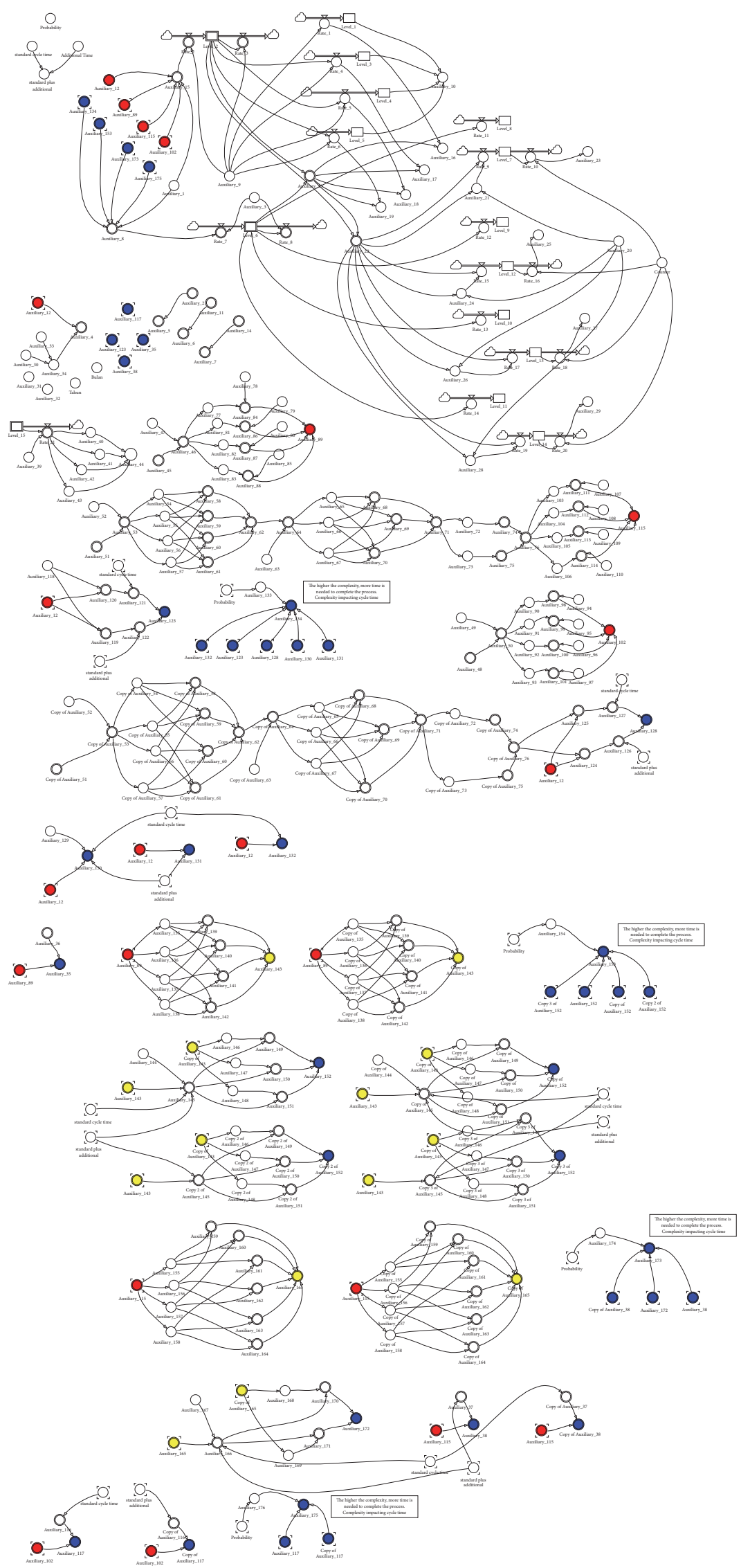

FIGURE 15: The next or future stage of procurement model developed using system dynamics methodology. 


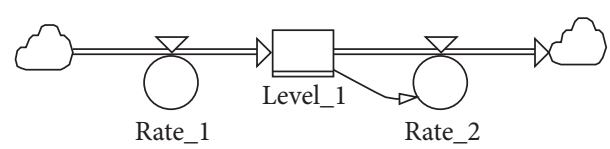

FIGURE 16: Water tank model developed using system dynamics methodology.

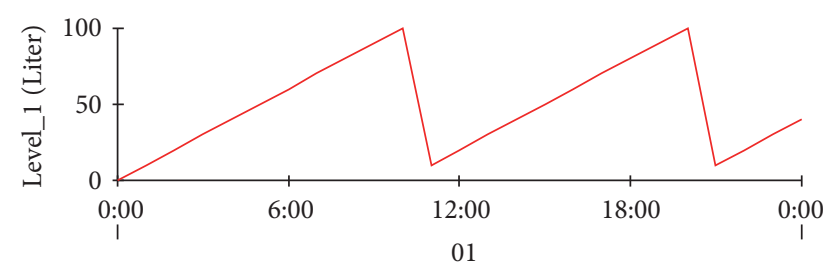

Figure 17: The behavior of Scenario A.1's Level_1.

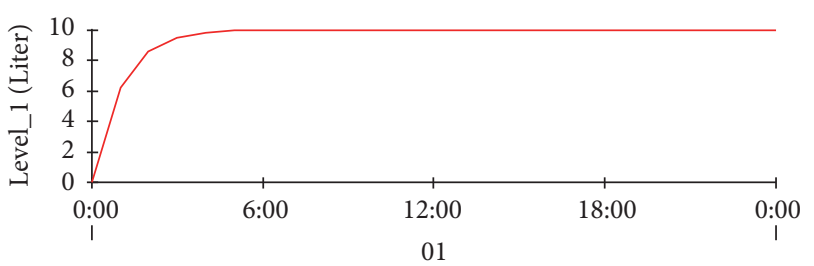

Figure 18: The behavior of Scenario A.2's Level_1.

tank reached the level of 100 Liters or more, it (i.e., the tank) will be flushed automatically and the whole process of filling up the tank is repeated as shown in Figure 17. The behavior of Level_1 as shown in Figure 17 especially before flushing could be explained by the following (mathematical) formula:

$$
\text { Level_1 } 1= \begin{cases}10(t-0) ; & t=1,2, \ldots, 10 \\ 10(t-10) ; & t=11,12, \ldots, 20 \\ \vdots & \vdots\end{cases}
$$

Scenario A.2. The following are the equations used in water tank model: Rate $\_1=10$ Liter/Hour; Level_1 $=0$ Liter (at the beginning); Rate_2 = Level_1 Liter/Hour. Over a period of 24 hours where the water tank is empty at the beginning, water flows into the tank at the rate of 10 Liters per hour. Water in the tank increases exponentially until it reaches stationary level at (approximately) 10 Liters. The behavior of Level_1 as shown in Figure 18 could be explained by the following (mathematical) formula:

$$
\text { Level_ } 1=10\left(1-e^{-t}\right), \quad t=1,2, \ldots
$$

\section{Additional Points}

Highlights. (i) Using system dynamics methodology, a procurement model is developed; (ii) two scenarios are incorporated into the said (procurement) model; (iii) the said model produces total number of days involved in completing procurement process.

\section{Conflicts of Interest}

There are no potential conflicts of interest in the study.

\section{Acknowledgments}

The author would like to thank Roswidah Mat Lui of Telekom Research \& Development Sdn Bhd for providing invaluable insight into procurement process.

\section{References}

[1] B. Asgari and M. A. Hoque, "A system dynamics approach to supply chain performance analysis of the ready-made garment industry in Bangladesh," Ritsumeikan Journal of Asia Pacific Studies, vol. 32, 2013.

[2] A. Kussainov, "Use of system dynamics and simulation in modeling and analysis of vaccine supply chain management," Information technologies, Management and Society, vol. 8, no. 1, pp. 32-37, 2015.

[3] Z. A. Malik and J. K. Cheng, "A system dynamics model to understand the interrelationship between different knowledge areas in construction project," International Journal of Business Management, vol. 2, no. 1, 2017.

[4] V. Latorre, M. Roberts, and M. J. Riley, "Development of a systems dynamics framework for KPIs to assist project managers' decision making processes," Revista de la Construccion, vol. 9, no. 1, pp. 39-49, 2010.

[5] W. Cahyo, K. O. El-Akruti, R. Dwight, and T. Zhang, "A resources provision policy for multi-unit maintenance program," in 8th World Congress on Engineering Asset Management \& 3 rd International Conference on Utility Management \& Safety, pp. 1-12, 2013.

[6] A. Sadreddin, R. Sawan, and A. Schiffauerova, "Using system dynamics approach to model cost of quality in the procurement process of the construction industry," in Proceedings of the First Asia-Pacific System Dynamics Conference of the System, Tokyo, Japan, 2014.

[7] K. Ross-Smith and M. Yearworth, "Dynamics of operational procurement: systems modelling for performance tracking and auditing," in Proceedings of the The 29th International Conference of the System Dynamics Society, Washington, USA, 2011.

[8] S. Croom and R. Johnston, "E-service: Enhancing internal customer service through e-procurement," International Journal of Service Industry Management, vol. 14, no. 5, pp. 539-555, 2003.

[9] A. C. Marquez and C. Blanchar, "The procurement of strategic parts. Analysis of a portfolio of contracts with suppliers using a system dynamics simulation model," International Journal of Production Economics, vol. 88, no. 1, pp. 29-49, 2004.

[10] J. Mula, F. Campuzano-Bolarin, M. Díaz-Madroñero, and K. M. Carpio, "A system dynamics model for the supply chain procurement transport problem: Comparing spreadsheets, fuzzy programming and simulation approaches," International Journal of Production Research, vol. 51, no. 13, pp. 4087-4104, 2013. 
[11] M. Marinkovic, Designing outcome based performance management systems through system dynamics modeling to frame corruption behavior in public procurement [Ph.D. thesis], Universita Degli Studi Di Palermo, 2015.

[12] J. W. Forrester, Some basic concepts in System Dynamics, Sloan School of Management, Massachusetts Institute of Technology, Cambridge, UK, 2009.

[13] B. W. Silverman, Density Estimation for Statistics and Data Analysis, Chapman \& Hall, London, UK, 1986.

[14] L. Sachs, Applied Statistics: A Handbook of Techniques, SpringerVerlag, 2nd edition, 1984. 


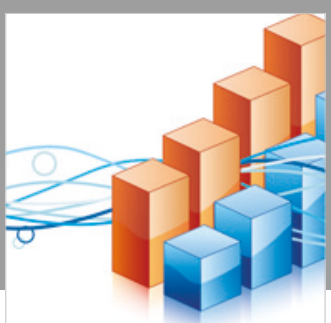

Advances in

Operations Research

\section{-n-m}
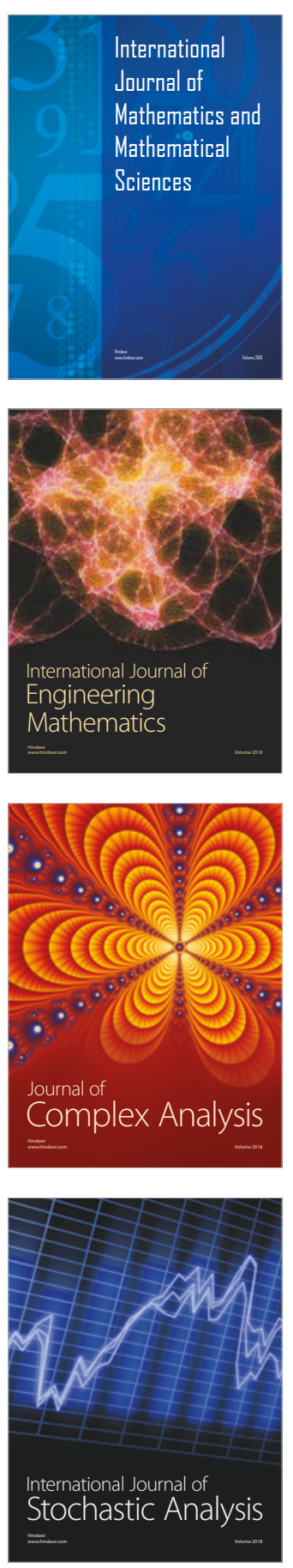
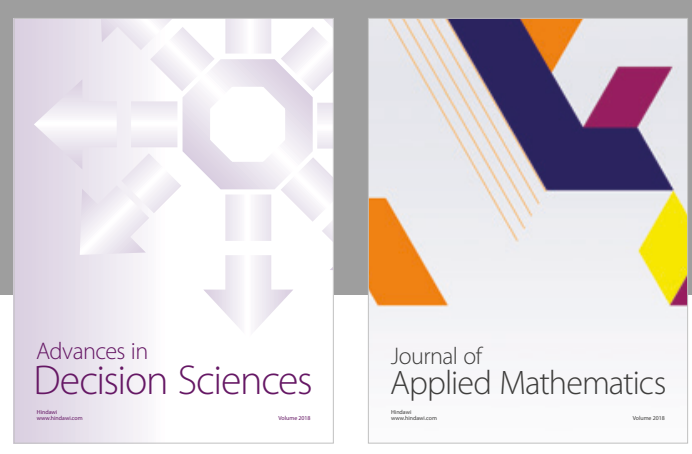

Journal of

Applied Mathematics
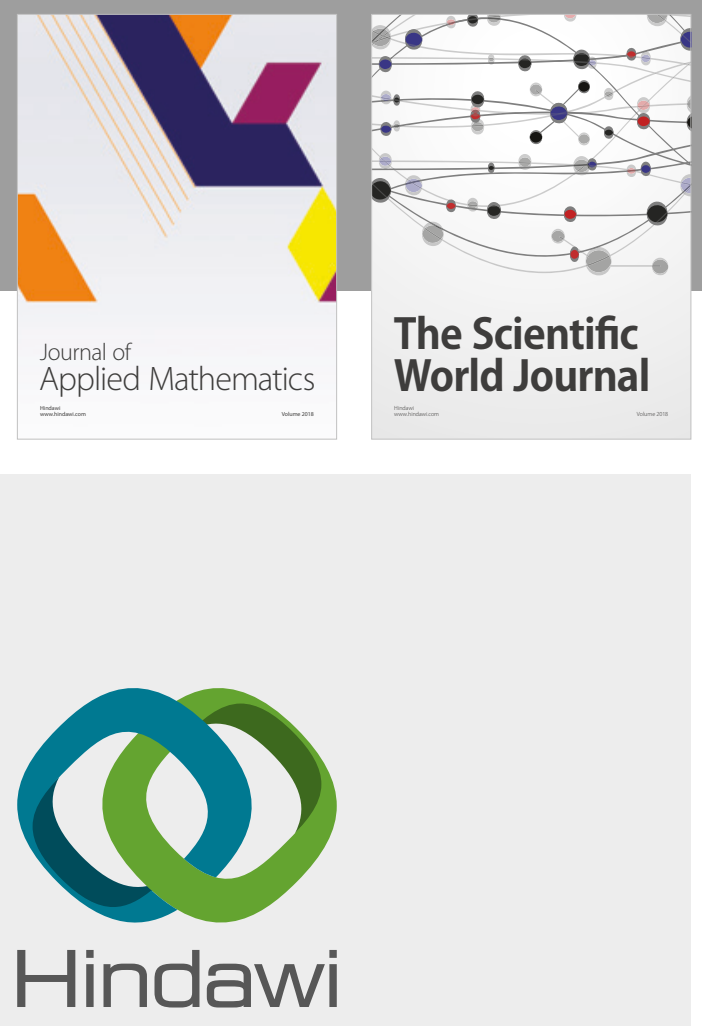

Submit your manuscripts at

www.hindawi.com

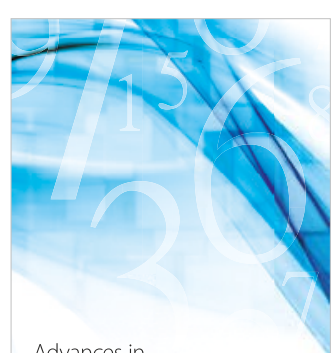

Advances in
Numerical Analysis
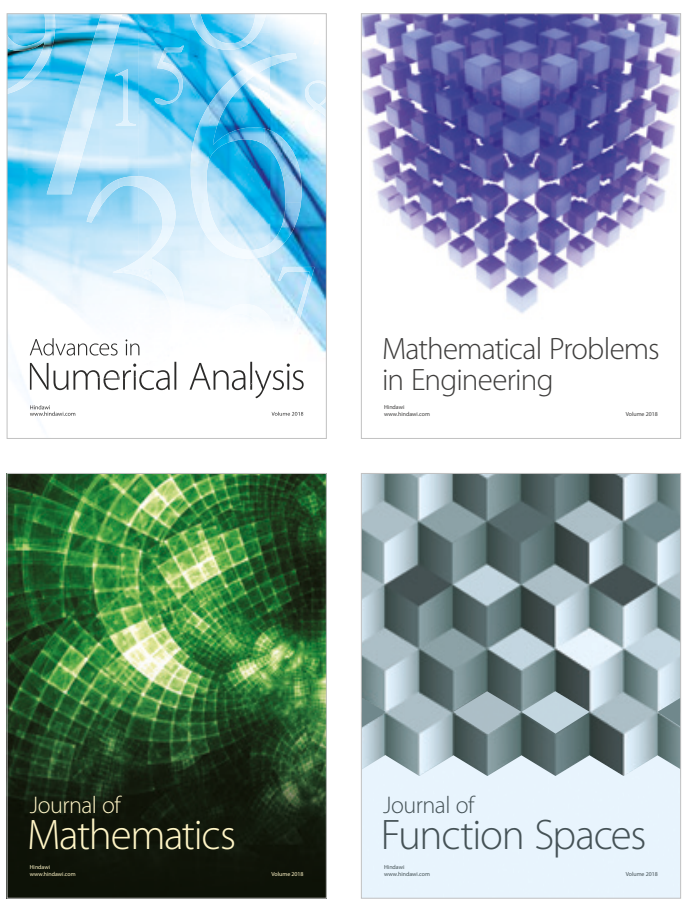

Mathematical Problems in Engineering

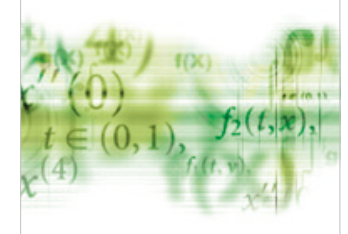

International Journal of

Differential Equations

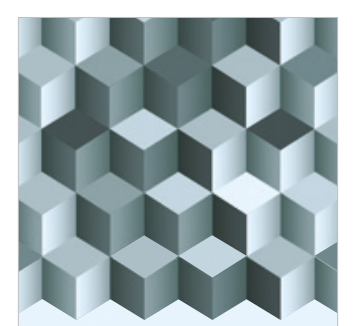

Journal of

Function Spaces

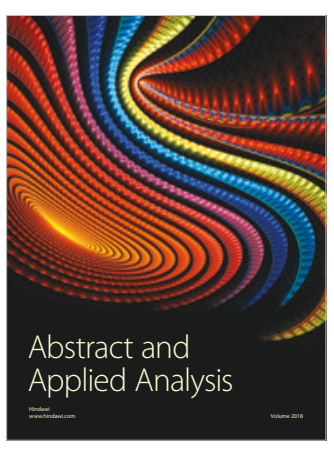

The Scientific

World Journal

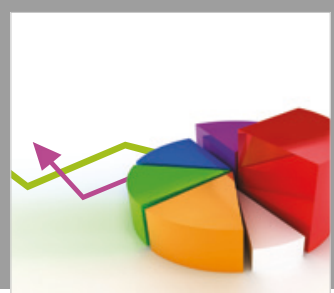

Journal of

Probability and Statistics
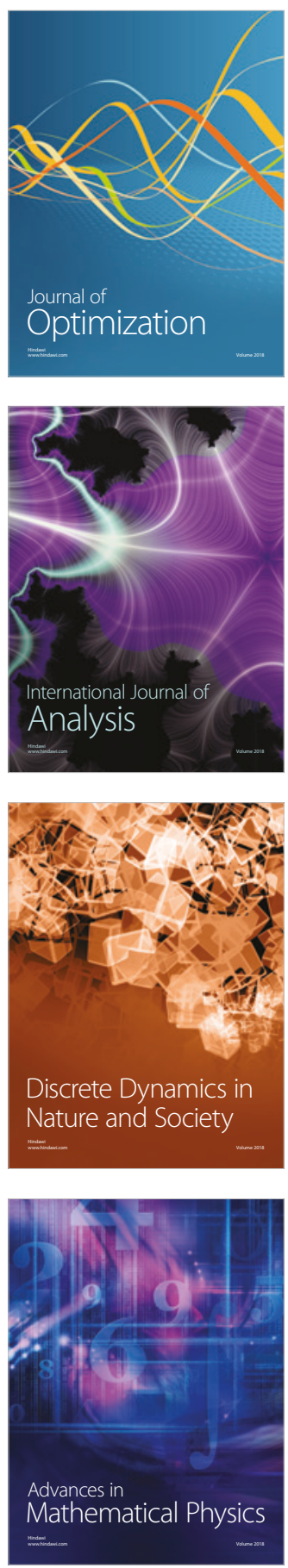